\title{
CRISIS Y ORIENTACION. APUNTES SOBRE EL PENSAMIENTO DE KARL MANNHEIM ${ }^{1}$
}

\section{Ignacio Sánchez de la Yncera}

Universidad del País Vasco

\section{INTRODUCCION}

Cuando estamos a un paso del centenario del nacimiento de Karl Mannheim (Budapest, 27-3-1893 / Londres, 9-1-1947), puede ser oportuno hacer algunas observaciones sobre su obra y sobre su personalidad intelectual que vengan a poner de relieve su vigencia. La sociología tiene en Mannheim una figura emblemática de primer orden, y lo tiene no sólo desde el punto de vista histórico, sino, a nuestro entender, desde la perspectiva de los empeños de revisión sistemática del paradigma teórico de la sociología.

Entendemos que la figura intelectual de Mannheim reúne conspicuamente los rasgos del modelo de la sociología teórica posterior a Max Weber, a partir de sus teorías de la acción y la comprensión ${ }^{2}$. Pero su formación filosófica, privile-

Aunque ha sido parcialmente reelaborado, este artículo está basado en el texto inédito de la comunicación presentada por el autor ante el grupo de trabajo de «Teoría Sociológica» en el «IV Congreso Español de Sociología», celebrado en Madrid durante los días 24-26 de septiembre de 1992.

${ }^{2}$ En este sentido, y si nos atenemos a la tipología propuesta por Martín López, el pensamiento sociológico de Mannheim camina próximo a teorías racionalistas como las de Sombart, Tönnies y Von Wiese y dialoga intimamente con ellas, aunque traza su propio camino original, que debería ser convenientemente explorado. No obstante, en una primera aproximación, que aquí sólo va a quedar apuntada sin mayor justificación, podría decirse que el sentido del pensamiento de Mannheim se sitúa en un plano intermedio entre la sociología histórica de Freyer y la «doctrina de la relación» (o «del vínculo») de Von Wiese, 
giadamente adquirida junto a algunos de los pensadores más insignes de su tiempo, permitió que Mannheim se midiera sin ambages con las aporías teóricas y metodológicas de fondo que no habían sido abiertamente tratadas, al menos de manera explícita y cabal, por el propio Max Weber. Además, Mannheim bosquejaría una interesante y prometedora propuesta de renovación de la sociología: creemos que en su obra, especialmente en la del período que nos va a ocupar, está presente una sugestiva teoría de la intersubjetividad. Aunque no se haya proseguido en directa conexión con su obra, el estado actual de la investigación permite recuperarla, actualizarla y revisarla desde otros enfoques que han ido naciendo, procedentes muchos de ellos de las mismas fuentes intelectuales que Mannheim conoció y aprovechó, merced a que su condición de testigo privilegiado del origen de algunos de los más fecundos puntos de vista de la filosofía del siglo XX se unió a la sagaz mirada de un pionero, que veía más allá del alcance de la vista de sus contemporáneos 3

al tiempo que dedica una gran atención a la sociología del espíritu, como hiciera Sombart, puesto que Mannheim veía en la sociología de la cultura la contrapartida necesaria para compensar la exagerada insistencia en lo estructural que se estaba haciendo crónica en la sociología. (Dicho sea esto a pesar de que el propio Von Wiese consideraba, creo que injustificadamente, que Mannheim representaba más bien una sociología del espíritu que dudaba sobre la existencia de una realidad interhumana distinta a la de las interpretaciones presentes en las representaciones colectivas de la vida social.) Vid. E. MARTín López, Sociología general I: la sociologia como ciencia de las relaciones sociales, Barcelona, 1969, pp. 28 y ss., y, también, el tercer capítulo del tex to impreso para el 1 Seminario de Sociología del Instituto de Estudios de Sanidad y Seguridad Social, de junio de 1979. El comentario de Leopold vON WIESE aparece en su Sistema de sociología general, Puebla (México), Ed. Cajica, 1959 , p. 91

${ }^{3}$ Conviene decir que tanto el sustrato intelectual como la intención teórica de Mannheim tienen mucho en común con otra línea autónoma de trabajo intelectual que viene en los últimos años inspirando los esfuerzos de renovación de la sociología, a partir, sobre todo, de la obra de G. H. Mead: el llamado «pragmatismo norteamericano». En los últimos escritos de Mannheim hay evidencias netas de la comodidad con la que Mannheim conecta con la psicología social norteamericana de G. H. Mead y J. Dewey; pero es evidente que los escritos de los años veinte y treinta sitúan a Mannheim en la misma línea de orientación teórica que está presente en el fondo de los trabajos sociológicos de los pragmatistas norteamericanos más innovadores (advierto que debe ponerse cuidado al interpretar el término pragmatismo, que -aplicado a propuestas tan fecundas y poco explotadas como las presentes en la obra de Peirce, de Mead y en la de los últimos años de Deweydeberíamos sustituir por «teoría de la inter-acción»), lo cual no es tampoco difícil de entender si se tiene en cuenta que dichos pensadores estaban tratando de aportar a la sociología, entonces incipiente en los Estados Unidos, las luces más fecundas que aún eran aprovechables del planteamiento procesal de la experiencia y de la naturaleza derivado de la filosofía hegeliana, tomadas ya totalmente al margen de la pretensión de verdad del propio sistema de Hegel. Vid. I. SÁNCHEZ DE LA YNCERA, Interacción y comunicación. Aproximación al pensamiento de George Herbert Mead, Pamplona, Ediciones Eunate, 1990, e «Interdependencia y comunicación. Notas para leer a G. H. Mead», Revista Española dE Investigaciones Sociológicas, 55 (1991), pp. 133-164. Pero la actualidad de los trabajos de Mannheim resalta más aún si, además, cabe decir otro tanto con respecto a enfoques fenomenológicos de la sociología, como los de A. Schutz, que aparecen anticipados en algunos aspectos sustanciales por Mannheim a partir de la lectura y el contacto directo con Husserl, pero planteados desde una visión más limpia de la intersubjetividad, que es probablemente, por contra, uno de los puntos débiles del planteamiento del sociólogo austríaco. Por otra parte, creemos que hay en Mannheim una gran sintonía de fondo, que 
Pero como la empresa de esclarecer globalmente el pensamiento de Mannheim excede con mucho el alcance razonable de un trabajo como éste, nos vamos a limitar aquí a enunciar una serie de observaciones sobre las propuestas que realizó en el curso de los años veinte, en un momento decisivo de su vida intelectual que merece un análisis que apenas se ha realizado. Si bien el estudio de las obras de esos años no permite presentar adecuadamente la semblanza de su personalidad intelectual - puesto que muestran sobre todo la figura de un teórico ocupado en los grandes temas de la filosofía de su tiempo, y Mannheim no fue sólo eso--, su conocimiento favorece la percepción de la magnitud de sus empeños y ayuda a notar la coherencia de los diversos trabajos que acometió a lo largo de su vida intelectual.

Se trata precisamente de la época en que Mannheim vivía refugiado en Alemania, desde que en 1919 el golpe de Estado de Von Horty diera al traste con el régimen nacido de la revolución socialista que acababa de instaurarse en su patria, Hungría, régimen en el que su primer mentor, Gyorgi Lukàcs, recién incorporado al movimiento comunista, había protagonizado papeles de primer orden. Son sus años de trabajo en la Universidad de Heidelberg, iniciados bajo la dirección de Alfred Weber, durante los cuales obtuvo la habilitación como profesor en 1925.

Diversas razones permiten destacar este período, que Loader considera como el primer periodo de transición intelectual de Mannheim ${ }^{4}$. En primer lugar, es precisamente en esta época cuando Mannheim perfila su propio camino intelectual autónomo, mientras se afianza en la carrera académica. Son los años previos a la publicación del libro Ideologie und Utopie, en 1929, la cual, como es sabido, tras situarle en el primer plano de actualidad científica, le iba a ayudar decisivamente en el acceso a la cátedra de Sociología en Frankfurt ${ }^{5}$. En

puede percibirse en muchos puntos, con las propuestas teórico-metodológicas que derivan del planteamiento maduro de la hermenéutica propuesto por P. Ricoeur, que, si son, sin duda, mucho más refinadas y actuales -..no en vano se han beneficiado con todo provecho de la riquísima herencia de la filosofía analítica, de la semiología y de la hermenéutica más reciente, que procede del Heidegger tardío y de Gadamer principalmente, además de otras fuentes desconocidas por Mannheim-, son afines a las cuestiones que Mannheim se planteaba sobre la interpretación, la intersubjetividad y, especialmente, sobre las representaciones colectivas y la identidad personal y social.

* En el aspecto biográfico, el trabajo más completo y documentado es el que Woldring incluye en su extensa monografia. Vid. H. E. Woldring, Karl Mannbeim. The Development of bis Thought, New York, Saint Martin Press, 1985, pp. 5-69. No obstante, en lo que concierne a la trayectoria intelectual de Mannheim, que es lo que aquí nos interesa, no conozco un trabajo más completo y luminoso que el de Colin LOADER. The Intellectual Development of Karl Mannbeim: Culture, Politics and Planning, New York, Cambridge University Press, 1985, que voy a seguir de cerca en buena parte de esta intervención. Sobre el punto concreto al que me refería, cfr. pp. $1-27$ y 66-94. Vid., también, B. S. Turner, «Preface to the New Edition», en MANnHEIM, Ideology and Utopia, nueva edición, Londres, Routledge and Kegan Paul, 1991, pp. XXIII-LIII. En mi opinión, este trabajo está fuertemente influido por el vigoroso estudio de Loader.

5 Y eso a pesar de que su condición de inmigrante judio suponía un obstáculo para entrar en la función pública en la Alemania de aquel tiempo; datos hay, excelentemente registrados por Woldring, de que el camino de Mannheim — pese a la rapidez de su nacionalización como alemán, facilitada por su sobresaliente desempeño académico- hubo 
segundo lugar, en estos años toma cuerpo la determinación de Mannheim de dedicarse a la sociología, y se perfila su propia forma de afrontar los problemas metodológicos que conciernen a ésta, que él aborda en directo y en el plano más profundo a partir de los principales proponentes de la cuestión en el mundo intelectual alemán. $Y$, finalmente, en sus escritos de esta época pueden encontrarse algunas de las claves que permiten la presentación unitaria de su trayectoria de pensamiento, frente a la injustificada tendencia a presentarla como carente de unidad lógica y presidida por drásticos cambios de orientación ${ }^{6}$.

Entendemos que esas caracterizaciones pierden de vista los problemas sistemáticos que ocuparon su atención intelectual. Frente a ellas, tratamos de presentar la coherencia global de sus trabajos, aunque sea cierto que Mannheim no explicitó su pensamiento, de vocación sistemática, en forma de tratados suficientemente elaborados y extensos. Además de que ese hecho puede explicarlo, en parte, su temprana muerte, hay que anotar al respecto su firme convicción acerca de la necesidad de tratar ensayísticamente los problemas - tenía conciencia de estar dando «pasos iniciales de tanteo» hacia una nueva perspectiva, y se veía necesitado de autocrítica y revisión continuas.

De hecho, Mannheim veía natural que la forma de proponer pensamientos inaugurales fuese fragmentaria y ensayística, como, según él, ocurría con los trabajos sociológicos de Max Weber, Dilthey, Sumner, W. I. Thomas y los suyos propios ${ }^{7}$. Pero también es cierto, como en alguna ocasión ha comentado Martín

de toparse crudamente con tales obstáculos, aunque saliera bien librado de ellos. Cfr. WOLDRING, op. cit, pp. 26-35.

6 Ese es el caso, por ejemplo, del tratamiento un tanto arbitrario y tajante de la evolución intelectual de Mannheim que realiza G. W. Remmling, aun siendo un consumado especialista en el estudio de su obra. Vid. G. W. Remmling, «EI significado y el desarrollo de la sociología de K. Mannheim», en G. E. Remmling (comp.), Hacia la sociologia de conocimiento, México, FCE, 1982, pp. 285-299. Lo mismo hay que decir del trabajo, más reciente, de N. Abercrombie y B. Longhurst, «Interpreting Mannheim», Theory, Culture and Society, 2, 1 (1983), pp. 5-15. Un tratamiento más adecuado de la cuestión puede encontrarse en D. Kettler, V. Meja y N. STEHR, Karl Mannheim, Londres y Chichester, 1984. Son interesantes las sugerencias que hace Susan Hekman en un artículo de réplica al de Abercrombie y Longhurst. Dicha autora subraya las inconsistencias que encuentra en su obra y acierta a reconocer su unidad de intención, que ella interpreta como la continua búsqueda de una base epistémica para las ciencias sociales sustitutiva de las aportadas por la Ilustración y el positivismo. Según ella, esa alternativa nunca fue lograda, pero fijó la atención de Mannheim en el problema de la relación entre pensamiento y existencia, y le acercó paulatinamente a una posición hermenéutica. Vid. S. HEKMAN, «Re-interpreting Mannheim», Theory, Culture and Society, 3, 1 (1986), pp. 137-142.

Mannheim explica con claridad su forma de-trabajar en un pasaje que nos vamos a permitir reproducir casi completo. El fragmento se inicia justificando la denominación de ensayos para los trabajos que componen uno de sus libros, y continúa así: «éstos [los ensayos] son simples pasos de tanteo... con el ataque impetuoso no lograríamos más que una colección de observaciones fortuitamente conceptuadas o, lo que es peor todavía, el relicario de una imaginería pretérita... Montaigne llamó a sus obras “ensayos”. El sociólogo apreciará en particular esta expresión que manifiesta la aceptación prudente y franca de una visión fragmentaria de las cosas... Los pasos iniciales deben consistir en análisis críticos que pueden liberar a los elementos de la nueva perspectiva de las ataduras de hábitos de pensamiento anticuados e insostenibles. Una continua autocrítica y la revisión periódica de lo que parezca ser un nuevo avance, es lo único que puede preservarnos de la tentación de 
López ${ }^{8}$, que su tarea teórica estuvo siempre interferida por una inquietud angustiada y un sentido de urgencia hacia los problemas culturales y políticos de su tiempo, que, si bien llenaron su obra de valor testimonial y de interés históricopolítico, posiblemente le restaron potencia elucidadora para las cuestiones teórico-sistemáticas.

\section{BAJO LA SOMBRA DE HEGEL: LAS BASES DE LA SOCIOLOGIA DE MANNHEIM}

Teniendo en cuenta todo esto, y anticipando otras contribuciones de mayor alcance que tenemos en curso, respecto a las cuales no es ésta sino un pequeño anticipo al amparo de la proximidad del aniversario, hemos elegido como tema de este trabajo los puntos de vista propuestos por Mannheim en esa época de transición.

En estos años, en la mente de Mannheim, y en sus propuestas historicistas" de carácter abiertamente filosófico - escritas con personalidad propia, pero dentro de una atmósfera marcada por la crisis del sistema filosófico de Hegel-, empezaban a alumbrarse con toda claridad las consideraciones fenomenológicas y estructurales que habían de presidir todas sus propuestas sociológicas ${ }^{10} \mathrm{y}$

introducir a la fuerza experiencias nuevas en los moldes de sistemas ajados. Los investigadores que sitúan la búsqueda de soluciones auténticas por encima de la "aventura en busca de soluciones absolutas" no aceptarán panaceas ni fórmulas sucintas, en lugar de una comprensión paso a paso de una situación problemática. Esta es la razón del carácter fragmentario de los trabajos de Max Weber, Dilthey, Sumner y W. I. Thomas; y también de éste». K. Mannieim, Ensayos de sociologia de la cultura, Madrid, Aguilar, 1963 (v. o., 1930-35), pp. 46-47.

8 Me refiero a algunos comentarios surgidos en el curso de la conversación personal, pero también a una conferencia sobre Mannheim, dictada por Martín López durante el curso 1988-89, a la que tuve ocasión de asistir y cuyo texto original, que aún no ha sido publicado, conservo. Confieso que mi interés por trabajar en profundidad la obra de Mannheim creció con ímpetu a partir de aquella luminosa sesión.

9 Entre sus escritos de más marcado tenor historicista destaca el ensayo «Historismus», que se puede señalar como conclusivo de una primera fase en la evolución intelectual de Mannheim, como señalan WOLDRING, op. cit., pp. 103 y ss., y, especialmente, LOADER, op. cit., pp. 28 y ss., quien considera esta obra como la propuesta culminar construida por Mannheim frente al problema de la síntesis filosófico-cultural en que estuvo ocupado desde sus años de estudiante. Vid., también, G. W. Remmling, The Sociology of Karl Mannbeim, Londres, Routledge and Kegan Paul, 1975, pp. 13 y 36. Mannheim vio el historicismo como la «fuerza cultural» representativa de una nueva concepción, esencialmente dinámica a la vez que estructural, del mundo, que constituía una de las grandes evoluciones intelectuales del mundo occidental. Cfr. K. Mannheim, «El historicismo», en G. E. Remmling (comp.), Hacia la sociologia del conocimiento, México, FCE, 1982, pp. 141-157. Esta versión recoge la introducción del original «Historismus», publicado en Archiv für Sozialwissenschaft und Sozialpolitik, 52, 1 (1924), pp. 1-60; las referencias, a las pp. 141-143.

10 En la misma introducción a su ensayo sobre el historicismo, de 1924 , hay ya una referencia explícita a la sociología. En él señala que el historicismo no es ningún programa artificialmente ideado, sino la propia Weltanschauung, que nació tras haberse desintegrado la representación religiosa del mundo que dominó en el Medioevo y después de que la Razón supratemporal de la Ilustración se autodestruyera, y que existe únicamente desde que los problemas implicados en las nuevas maneras de enfrentarse a la vida han alcanzado el 
que, vistas en toda su profundidad y riqueza, permiten entender los episodios y el trazado general de su trayectoria intelectual como un todo unitario articulado con una fuerte cohesión lógica, sin menoscabo, no obstante, de la importancia de los cambios de énfasis y tampoco de la incidencia de los episodios históricobiográficos que zarandearon formidablemente la vida de Mannheim, haciendo de él, según su propia caracterización, un «refugiado» permanente ${ }^{11}$.

El estudio de ese período hace volver la vista sobre las líneas mayores de la epistemología sociológica y permite conectar, como anticipaba antes, con un Mannheim relativamente inédito, que estaba ya donde estamos en nuestros días al tratar de hacer avanzar las ciencias sociales, y que puede resultar de gran utilidad en los esfuerzos de revisión crítica de la filogénesis de la sociología.

Tal vez no sea suficientemente conocido que Mannheim asistió a las explicaciones inaugurales de la fenomenología (que proponían Husserl y Heidegger) ${ }^{12}$, aparte de conocer en sustancia las reflexiones historicistas de Dilthey, Weizsäcker y Tröltsch que mostraban la futilidad de los planteamientos positivistas, excesivamente romos en el plano de la interpretación y comprensión crítica de los problemas metodológicos de la ciencia en general y de las ciencias humanas en concreto. Además, Mannheim estaba viviendo en Heidelberg, donde permanecía viva la figura de Max Weber ${ }^{13}$, y salía de una dolorosa ruptura con su primer mentor, Gyorgi Lukàcs, del que le había separado, probablemente, la repugnancia que despertaba en el fino talante intelectual de Mannheim cualquier modo estrecho de interpretar y vivir la vocación intelectual (como pudo ser, para él, el compromiso partidista adoptado por Lukàcs al incorporarse al Partido Comunista húngaro). Pero había recibido ya de Lukàcs - bajo cuya influencia se

nivel de la conciencia de sí mismos, y declara que «nuestra visión de la vida se ha vuelto ya completamente sociológica y la sociología es una de esas esferas que, cada vez más dominadas por el principio del historicismo, reflejan más fielmente nuestra nueva orientación vital»; cfr. ibidem, pp. 141-142; la cita, de la p. 141.

11 Mannheim escribió sobre esta figura del «refugiado» en un artículo titulado «The Function of the Refugee», New English Weekly, 27 (19 abril 1945), pp. 5-6.

12 Mannheim veía en la fenomenología la contrapartida del análisis estructural de la sociedad desarrollado desde el racionalismo como una lógica de las formaciones culturales objetivas. Cfr. K. MANNHEIM, «A sociological theory of culture and its knowability (conjunctive and communicative thinking)», en K. MANNHEIM, Structures of Tbinking, compilado por D. Kettler, V. Meja y N. Stehr, Londres, Routledge and Kegan Paul, 1982, pp. 141-248; para la cita, p. 169. Si este punto de vista podía ser menos comprensible en aquellos años, no cabe duda de que algo de eso ha habido después, a partir de los apuntes sociológicos presentes en la versión hermenéutica de la fenomenología que está presente en las obras más maduras de pensadores actuales, entre los que destaca, desde mi punto de vista, Paul Ricoeur. Vid,, especialmente, P. Ricoevr, «The Model of the Text: Meanigful Action Considered as a Text», Social Research, 38 (3), 1971, pp. 529-562. Simonds y Bauman sitúan a Mannheim en la tradición hermenéutica. Según ellos, sus estudios sobre el pensamiento conservador, las utopías y la conciencia son ensayos hermenéuticos que tratan de entender el significado de esos fenómenos como productos culturales. Vid. A. P. Simonds, Karl Mannheim's Sociology of Knowledge, Oxford, Clarenton Press, 1978, y Z. Bauman, Hermeneutics and Social Science, Londres, Heinemann, 1978.

${ }^{13}$ En los varios círculos intelectuales de Heidelberg, especialmente en el que se reunía en torno a la viuda de Weber, Mannheim frecuentó a K. Jaspers, H. Rickert, E. Bloch, $M$. Lederer y $M$. Buber, entre otros. 
mantuvo desde 1910 hasta 1919- el aprecio de la filosofía hegeliana, además de una inteligente comprensión del valor del diagnóstico marxiano -que tomó de una forma muy personal e independiente en lo que tenía de útil para abordar el problema de la crisis de la civilización ${ }^{14}$ - y una cuidadosa atención tanto a la sociología formal de Simmel ${ }^{15}$, cuyas lecciones escuchó personalmente en Berlín entre 1912 y 1914, como a la sociología comprensiva de Max Weber. También la influencia de Lukàcs pudo llevar a Mannheim a París en 1914 para asistir a las clases de Henri Bergson. Además, conocía a fondo la sociología clásica europea y las obras de Sombart, Von Wiese y Tönnies, entre otros, así como los primeros frutos de la incipiente sociología norteamericana.

Sólo en atención a esos apuntes, bien se puede decir que Mannheim estaba intelectualmente situado en el lugar justo y en la mejor compañía para emprender su tarea de teórico de la sociología, pero también que Mannheim es una figura que no puede eludirse al buscar en la historia de la sociología puntos de apoyo para ir adelante.

Aun conociendo bien los planteamientos neokantianos que predominan en las ciencias del espíritu de esos años, bien vigentes en la atmósfera de la Universidad de Heidelberg, Mannheim siente mayor aprecio por el poder elucidador

${ }_{14}$ Estudiosos como Remmling, Woldring y Loader mantienen distintas posiciones sobre la influencia de Lukàcs sobre Mannheim, especialmente en torno a la génesis de Ideologie und Utopie (1929). Pero resulta significativo observar, siguiendo a Loader, que Mannheim, en su ensayo de 1924 sobre el bistoricismo, que escribió después de haber leido Historia y conciencia de clase (Lukàcs, v. o. 1923), alude únicamente al historicismo estético de Lukàcs, de fuerte inspiración hegeliana, y presta atención a su visión renovada y no determinista de la dialéctica marxista, pero no acepta su forma de resolver el problema de la dicotomía teoría-praxis a partir de la asignación de un papel central a la supuesta universalidad de la conciencia del proletariado. Lo mismo podría decirse con respecto a Ideologie und Utopie, obra en la que - como ha subrayado Loader, contra la creencia frecuentemente publicadala influencia del espíritu de Historia y conciencia de clase es sólo secundaria. Loader sostiene la directa vinculación del original alemán de esa obra central de Mannheim con los escritos de Max Weber sobre la política y la ciencia. Cfr. C. LOADER, op. cit., pp. 95 y ss. Vid. M. Weber, El político y el científico, Madrid, Alianza, 1986.

${ }_{15}$ El reconocimiento que a Mannheim le merece la obra de Simmel queda fuera de duda, como lo demuestra este texto: «la sociología opera cómodamente dentro de los límites definidos primero por Simmel... Sigue siendo seguro y practicable delinear, con Simmel, los límites del campo de la sociología como el de las "formas de asociación"》. K. ManNheim, Ensayos de sociología de la cultura, op. cit., pp. 39-40. Pero, para Mannheim, esa «sociología de las formas de asociación» debía complementarse con su contrapartida, la ciencia de las ideas o de las representaciones sociales, puesto que no hay asociación sin comprensiones peculiares, ni a la inversa. Cfr. ibidem, p. 40. Muy lejos estaba, además - como ha señalado Loader-, de la actitud resignada de Simmel frente a la crisis cultural — que calificaba de tragedia-. La búsqueda optimista de soluciones adecuadas a la situación está presente en toda la obra de Mannheim. En contraste con Simmel, que padeció siempre en Alemania las consecuencias de su condición de outsider, Mannheim viviria siempre con conciencia de «refugiado», de portavoz de un grupo de intelectuales - la intelligentsia-, con espíritu de misión. Mientras en la visión de Simmel la reificación de las formas culturales sólo podía superarse por medio de una energía vital nueva $-\mathrm{y}$ por tanto aún carente de forma, pero, a su vez, abocada sin remedio a la reificación-, Mannheim creía, en cambio, en las virtualidades reparadoras de un estrato intelectual crítico y formal, al que atribuía la función antitética necesaria para abrir paso a una nueva síntesis espiritual, y que se sustraería al destino trágico en que pensaba Simmel. Cfr. C. LOADER, op. cit., pp. 63-65. 
de los problemas de la cultura que muestra el planteamiento dialéctico de raigambre hegeliana ${ }^{16}$. No obstante, se queda con el aspecto formal de la explicación dialéctica, desentroncándola del sentido metafísico que tenía en la obra de Hegel, como lo demuestra un ensayo escrito a comienzos de los años trein$\mathrm{ta}^{17}$, en el que trata de fundamentar su concepción de la sociología de la cultura. El ensayo se abre con una advertencia sobre la inutilidad de la simple restauración de una tradición muerta: según él, la magia de la filosofía de Hegel y la situación histórica con la que concordaba ya habían desaparecido. Pero enseguida declara rotundamente que del potencial de la filosofía de Hegel no debe desperdiciarse lo que tiene de perdurable - su aguda conciencia de situación-, y dice que nunca ha conseguido la filosofía restablecer un contacto tan estrecho con la realidad de su tiempo como el que exhibe la obra de Hegel. «Nunca ha vuelto [la filosofía] a ser capaz de afirmar su supremacía sobre los intereses especializados y parciales sobre los asuntos humanos.» $\mathrm{Y}$, por eso, algunos de los planteamientos de la Fenomenología del espíritu no sólo están en pie, sino que exigen atención. Concretamente, dirá: «podemos todavía encontrar un mensaje vivo en la pretensión de que los conceptos no pueden ser aprendidos en un ataque frontal, sino a través de la comprensión de sus inserciones sociales e históricas» ${ }^{18}$.

Las consecuencias del mantenimiento de esta recepción de Hegel se manifiestan principalmente en el plano epistemológico. Mannheim sostiene, desde sus primeros escritos, que todo intento de negar la presencia de supuestos ontológicos en cualquier teoría se convierte, irremediablemente, en una presentación embozada de planteamientos que derivan de supuestos de ese tipo ${ }^{19}$. Si esa convicción adquiría ya, a mediados de los años veinte, un sentido general que caracterizará en adelante sus indagaciones sobre la raigambre social de las ideas y de las representaciones de la realidad social, poco tiempo después, vinculando su posición a la herencia de Hegel, la iba a expresar así: «las ideas poseen un significado social que su análisis frontal —es decir, inmanente- no pone de manifiesto. Siendo así, las ideas pueden ser estudiadas en el contexto social en el que son concebidas y expresadas, y es en ese ensamblaje semántico donde su significado se hace concreto» ${ }^{20}$.

16 Cfr. K. Mannheim, Structures of Thinking, op. cit., pp. 185 y ss.

17 K. Mannheim, «Hacia una sociología del espíritu», en K. Mannheim, Ensayos de sociología de la cultura, op. cit., pp. 33-134. (El traductor de la edición española, Manuel Suárez, aclara que el amplio sentido del término Geist hace recomendable el empleo de «cultura» para su versión, aunque esa opinión es muy discutible; vid. ibid., p. 35 , nota.) Pero ya antes había escrito Mannheim: «El nuevo idealismo reconstituido sólo toma de Hegel lo relevante para el método.» K. Mannheim, Structures of Thinking, op, cit., p. 168.

${ }_{18}$ Cfr. ibidem, pp. 35-38. Las citas corresponden, correlativamente, a las pp. 38, 37 y 36.

${ }_{19}$ Frente a Kant, alegará que su intento de construir una epistemología inmanentista sin presupuestos ontológicos esconde una hipostatización de un prejuicio ontológico que impide entender la relación de conocimiento como una relación existencial. Cfr. K. ManNHeim, Structures of Thinking, op. cit., p. 283.

${ }^{20} \mathrm{~K}$. Mannheim, «Hacia una sociología del espíritu», op. cit., p. 36. En el mismo contexto dice que «la Sociología del espíritu ha resultado ser la heredera del objeto de la especulación de Hegel». Ibid., p. 37. 
Si no es difícil ver, como se demuestra a continuación, que ese contexto teórico es esencial para entender sus propuestas historicistas, orientadas todavía por la búsqueda de una nueva síntesis cultural, es relevante comentar que esa misma atmósfera va a ser la que inspire su camino hacia la sociología. Pero no hay que perder de vista, aunque sea éste un asunto que vayamos a abordar más tarde, que la tarea sociológica que emprenderá inmediatamente tiene una clara vocación terapéutica frente a las deformidades epistemológicas de una sociología marcada por el espíritu de un tiempo que la había hecho reduccionista y parcelaria. De hecho, tratará de fundamentar la Sociología de la Cultura como una disciplina necesaria para articular la tarea de orientación en un mundo que ha quedado culturalmente roto a causa de los procesos de la civilización industrial.

En su trabajo sobre el historicismo, en el que subrayaba el carácter irrenunciable del punto de vista evolutivo que se iba adoptando en todas las parcelas del trabajo científico, Mannheim encontraba en la perspectiva historicista más bien la visión del mundo de una época que caía en la cuenta del carácter perspectivo y episódico de cualquier situación histórica, que una nueva síntesis esclarecedora aportada por la filosofía. Esa misma convicción se acusa aún más en dos escritos sociológico-culturales, donde reconoce que en nuestra época no es posible encontrar las condiciones ni el empuje idóneos para una nueva síntesis filosófica. La toma de conciencia de la perspectividad histórica, que en sí misma era un gran logro, había producido una especie de anemia espiritual que incapacitaba para la síntesis.

Pero lo que interesa destacar es que, según él, esa impotencia podía, a su vez, propiciar un aumento de la inteligencia del método, un incremento de la capacidad para reconocer cómo se producen las visiones del mundo y cómo éstas se elaboran crítica y esforzadamente en la forma de sistemas filosóficos. Las épocas creativas y productivas son ciegas — dirá- para las estructuras. No son capaces de hacerse cargo de su propio marco estructural, que es donde se están gestando las grandes concepciones. En cambio, en las etapas infecundas ese entramado puede quedar al descubierto. De hecho, Mannheim llega a hablar de una nueva creatividad que estaba formándose en una época como la suya, impotente para la creación de una nueva síntesis filosófica: «La nueva creatividad -escribe- estaría en la destreza y la mirada clara hacia las estructuras» ${ }^{21}$.

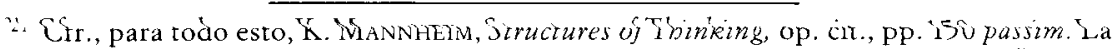
cita, de la p. 168. En mi opinión, el debate actual sobre la acción y la sociedad reflexivas, puesto de manifiesto de forma sobresaliente en las sesiones del grupo de trabajo de «Teoría Sociológica» del «IV Congreso Español de Sociología», conducidas por Rodríguez Ibáñez y Lamo de Espinosa, puede interpretarse como sintomático de una agudización de la actitud crítico-reflexiva motivada por una situación de crisis de crecimiento del pensamiento teórico análoga a la que se refería Mannheim. Remedando el discurso de Ramón Ramos, conviene decir que Mannheim es un autor con fortísima conciencia del carácter intrínsecamente paradojal de la acción social y de la reflexión sobre la acción social. En mi opinión, Mannheim se percata no sólo de la «reflexividad autoconsciente» y «autorreferente» del discurso de acción y de la acción social misma, sino también de la «reflexividad constitutiva» de aquéllos. Este asunto está entrañado en su penetrante ampliación del alcance crítico de la imputación ideológica y en su propuesta sobre el papel orientador de la freischwebende 
En todo caso, para él, la atmósfera idealista tiene el gran valor de ayudar a evitar la confusión de la verdad científica con la cuantificación abstracta de las realidades dotadas de una individualidad cualitativa, que predomina en la versión deforme de la realidad procedente de un cientificismo racionalista espurio. El idealismo había puesto de manifiesto la necesidad de no omitir el reconocimiento de la pertenencia de cualquier acto cognoscitivo a una relación existencial englobante entre el sujeto y el objeto, y es precisamente en ese punto donde la madurez crítica de la epistemología científica contemporánea tiende en muchos casos a brillar por su ausencia. No es otro el problema que sufre la sociología naciente ${ }^{22}$.

El reconocimiento del perspectivismo irremediable con el que se abordan siempre los asuntos humanos va a ser un punto de especial insistencia por parte de Mannheim. Cualquier intento de consagrar la conceptualización, como forma pura del conocimiento, como el conocimiento per se, es rechazable, y esconde una inaceptable reducción de las realidades concretas de vivencia y posición existencial que toda forma de abstracción presupone, aunque lo haga inconscientemente. Hacía falta una mejor comprensión de la coimplicación entre teoría y praxis para eludir la materialización de las abstracciones del procedimiento intelectual. Desde esta posición, se va a convertir en un defensor a ultranza de la comprensión interpretativa, como procedimiento adecua-

Intelligentz alfredweberiana (pero no sólo ahí, puesto que podría rastrearse en cada rincón de su obra); una Intelligentsia cuya funcionalidad, si se toma en el sentido literal de la propuesta de Mannheim, aparece neutralizada y condenada a una absorta perplejidad, poco menos que insuperable, si se analiza desde el discurso sistémico de la sociedad compleja; pero creo que se trata de una paradoja que, en efecto, no es definitivamente aporética, y cuya solución marcará los pasos siguientes de la génesis epistémica de la sociología: las paradojas fecundan el seno de la teoría. Sin embargo, la idea de la «reflexividad constitutiva» está presente en su obra de una forma sólo intuitiva y virginal - apenas alcanza el estatuto de lo temático-y, por tanto, no resulta elucidada como convendría al discurso altamente reflexivo que se hace preciso en la etapa presente de la historia de la teoría social. Me atreveré a decir que he encontrado, en cambio, un discurso de ese tenor —en un estado bastante más que embrionario- en las propuestas que Ricoeur hace sobre la estructura simbólica de la acción social, y sobre la tematización narrativa y teórica de la misma. Vid. P. Rrcoeur, Temps et Récit I, París, Ed. du Seuil, 1983, pp. 85-129; aunque para una comprensión cabal de ese asunto conviene leer la serie completa de esa obra. Vid., del mismo autor, «The Model of the Text...», op. cit., y, también, «Ideology and Utopia as Cultural Imagination», Philosophic Exchange, 2 (1976), pp. 17-28, así como «La structure symbolique de l'action», en Actes de la 14 Conférence de Sociologie des Religions, París, Centre National de la Recherche Scientiphique, 1977, pp. 31-50. Sobre el discurso y la acción social reflexivos, vid. R. Ramos, «Una aproximación a las paradojas de la acción social», ponencia presentada al IV Congreso Español de Sociología, Madrid, 24.26 septiembre 1992, cuya lectura puede completarse con la del libro de E. LAMO De Espinosa, La sociedad reflexiva, Madrid, CIS, 1990.

${ }^{22} \mathrm{Cfr}$. ibidem. En lo referente a la sociología, su punto de vista queda reflejado con la mayor claridad en el otro trabajo que venimos citando, donde afirma la necesidad de completar la «ciencia de la sociedad con una adecuada sociología de la cultura», entendida como el contrapunto necesario para combatir la materialización creciente de los esquemas de referencia de las investigaciones parcelarias, ciegas para la investigación interdependiente, que mantienen a las ciencias sociales en un estadio preliminar de desarrollo. Cfr. K. Mannheim, «Hacia una sociología del espíritu», en K. Mannheim, Ensayos de sociología de la cultura, op. cit., pp. 40-46. 
Uu pard abortar los asuntos de la cultura y del saber y, con ellos, de la realidad integra de la sociedad humana ${ }^{23}$. No obstante, el pensador húngaro tiene conciencia clara de que esa maduración del método de las ciencias humanas es un logro histórico, brindado por una situación espiritual específica, sin la cual no hubiera sido posible ${ }^{24}$.

Estos puntos de vista permiten abordar con más luz, a su vez, la cuestión de su postura respecto a la adaptación marxiana de Hegel, de la que aprovechará tan sólo la orientación positiva de la mirada hacia el condicionamiento de la vida social por los factores históricos infraestructurales, pero rechazando la reducción determinista de lo cultural al estatuto de mero epifenómeno de las relaciones productivas. Además, en la perspectiva socialista de los problemas del cambio social, encuentra un elemento básico con el que ha de contar cualquier intento de afrontar la situación cultural ${ }^{25}$.

\section{LA SOCIOLOGIA DE LA CULTURA Y LA SOCIOLOGIA DEL CONOCIMIENTO FRENTE A LA CRISIS DE ORIENTACION}

La preocupación de Mannheim por la orientación ante la crisis de la cultura es, por lo tanto, un foco principal de su pensamiento durante el período que estudiamos, el cual, como ya se ha dicho, presenta rasgos sustanciales de continuidad con los esfuerzos de síntesis filosófico-cultural de los primeros años ${ }^{26}$.

${ }^{23}$ Cfr. el parágrafo titulado «The subject-object relation in interpretative understanding», en K. Mannhlim, Structures of Thinking, op. cit., pp. 185-191.

${ }^{24}$ Según él, «la comprensión e interpretación inmanentes sólo son posibles en una época que esté diferenciada suficientemente como para que incluya, en su espacio experiencial, varios espacios experienciales particulares. Pues es, precisamente, mediante esos espacios particulares cómo la existencia del individuo que interpreta adquiere el único estado interior de espíritu que es idóneo para penetrar en una variedad de espacios idénticos». Ibidem, p. 248. El énfasis, de Mannheim.

25 Mannheim afirma que la lección que Hegel y su renacimiento entrañan puede aplicarse al fundador del materialismo histórico (Marx) y su escuela: «Un estudio crítico que se mantenga alejado de la disputa sobre la ortodoxia del materialismo histórico, puede todavía descongelar elementos de aquel sistema que conservan significado útil. Una aproximación fundamentalmente nueva al estudio de la cultura puede surgir de tales comienzos. Lo que se necesita es la observación de mentes abiertas e investigadores cuya sensibilidad para el pulso que late en el tiempo no esté disminuida por prejuicios doctrinales.» Según él, Weber, Sombart, Troeltsch y Scheler habían acertado ya a hacerlo con el materialismo histórico. Cfr. K. MAnnheim, Ensayos de sociología de la cultura, op. cit., p. 38.

26 Como ha explicado Loader a partir del análisis de sus escritos más tempranos, para Mannheim, la «tragedia» de la cultura comenzó con el rompimiento de la cultura orgánica que caracterizaba al mundo tradicional, que él presentaba en los términos de la conocida dicotomía de F. Tönnies, empleando el término Gemeinschaftkultur (cfr. p. 47 de K. ManNHEIM, «The Distinctive Character of Cultural-Sociological Knowledge», en K. ManNhEIM, Structures of Thinking, op. cit., pp. 31-139). Describía ese mundo a partir de tres elementos intimamente cohesionados - de forma que no podían ser propiamente considerados como dotados de identidad propia-: los individuos o almas (Seelen), que eran los creadores y receptores de significados; la cultura objetiva o visión del mundo (Weltanschaung), que sería el contexto global de significados y valores en los que participaban esos creadores y 
Pero la gran síntesis cultural que fuera su empeño de juventud, ya desde su precoz participación en los vibrantes círculos intelectuales húngaros, rezumantes de existencialismo y de utopismo intelectualista, se transforma en una directa atención a las constelaciones de factores político-sociales que subyacen detrás de las diferentes concepciones del mundo que, en nuestro tiempo, aparecen enfrentadas sin aparente posibilidad de conciliación.

Si la meta primordial sigue siendo procurar una visión que favorezca la orientación y la dirección de los procesos históricos, Mannheim empieza a abandonar la exclusividad que el universo de la alta cultura tenía en sus intentos iniciales de construir una respuesta frente a la crisis cultural. Y si el espíritu de síntesis, que domina de parte a parte su obra, resulta también patente en los trabajos de este período, dicho espíritu experimenta en este momento un cambio de signo. El problema principal se sigue planteando en el plano de la cultura, pero la atención se reorienta hacia la organización social, la cual se entiende como organización sustantivamente articulada a partir de visiones concretas del mundo que compiten para llevar a la práctica el tipo de organización que pretenden.

El nuevo empeño consiste en replantear el problema de la orientación en la vida social, en su doble aspecto subjetivo y colectivo, pero abordándolo siempre en el seno de esa realidad trágica de una cultura materializada y rota en mil pedazos, que, como tal, parece incapaz de cumplir su misión de orientar el obrar humano, y que tampoco admite una recomposición postiza desde la unilateralidad de una de las visiones fragmentadas que pudiera imponerse finalmente a las otras, logrando, en todo caso, una síntesis en abstracto... y en falso ${ }^{27}$.

Mannheim cobra paulatinamente conciencia de que sólo cabe trabajar a partir del necesario reconocimiento del pluralismo de posiciones y concepcio-

receptores, y las obras o productos culturales (Werke), que serían los vehículos portadores de significado intersubjetivo y que medían la comunicación dentro de una cultura. La crisis cultural consistiría en la disolución de ese mundo orgánico en el que los sujetos vivían inmersos, sin que tuviesen sentido de autonomía frente a la conciencia comunitaria; al disolverse éste, las relaciones del sujeto individual con el contexto total se hacen problemáticas. El concepto de cultura, antes inexistente e innecesario, surge para designar uno de los elementos de división: «la total objetivación del espíritu que se ha convertido en parte del legado humano». Cfr. K. MannHEIM, «Seele und Kultur» (1918), en Kurt H. Wolf (ed.), Wissenssoziologie, Neuwied, Luchterhand, 1970, pp. 66-84. Para la cita, p. 69. Los posibles intentos de reconciliación de lo subjetivo con lo objetivado pasan precisamente por el puente que podrían constituir los productos culturales. En los primeros escritos, Mannheim discute esa fragmentación del todo cultural en términos metodológicos y filosóficos y no a partir de un planteamiento sociopolítico, como hará ya durante este período de transición. Para todo esto, vid. C. LOADER, op. cit., pp. 28 y ss.

${ }^{27}$ El ensayo de 1924, reiteradamente mencionado, es ejemplar para tomar cuenta de esta nueva posición. En él se puede leer: «La combinación de una doctrina perspectivista (i. e., la presencia de diversos puntos de vista para mirar la historia y para pesarla a través de ellos) y un intento de síntesis sólo parece paradójica para un pensamiento que todavía no ha caído en la cuenta de que las soluciones mediante la síntesis sólo pueden ser eficaces después de agudizar radicalmente las antinomias.» Cfr. K. MANNHEIM, «A sociological theory of culture and its knowability...», op. cit. La cita, p. 178. La síntesis, diremos nosotros, no se consigue aplanando o suavizando perfiles, porque, entonces, los hechos se acaban volviendo siempre contra la teoría. 
nes del mundo; dar cuenta de ese pluralismo es el único medio que puede permitir la orientación. El espíritu de síntesis no se endereza ya a la obtención de una visión del mundo unitaria, sino al reconocimiento de la diversidad de intentos de orientación, con espíritu realista y conciliador. Esta toma de postura era revolucionaria frente a las tendencias predominantes en la intelectualidad alemana de ese momento - significativamente singularizables en ciertos aspectos de la posición de su segundo mentor, Alfred Weber-, que procuraban esa síntesis ignorando ese pluralismo y subsumiéndolo en un planteamiento monista (espiritualista) que Mannheim, siguiendo en este punto a Max Weber, consideraba ya inaceptable ${ }^{28}$.

En ese contexto hay que situar su modo de abordar la sociología. Pues si Mannheim ve la sociedad moderna sumida en una situación de disgregación cultural, cuya dirección sólo se intenta por medio de inconducentes y peligrosos planteamientos productivistas abstractos, en la sociología al uso encuentra esas mismas tendencias desorientadas y huecas en el modo de afrontar los temas de la vida social humana. La sociología, hija de la sociedad industrial, mira hacia ésta lastrada con los mismos defectos de enfoque que presidían los procesos del hipertrófico desarrollo industrial ${ }^{29}$.

Entiende que el racionalismo de la burguesía había impulsado unilateralmente el desarrollo de la vida social, centrándolo de forma desproporcionada en el plano instrumental. La uniliteralidad procedería de la aplicación directa del método de las ciencias naturales a los asuntos humanos. Al emplearse ese procedimiento racionalista y abstracto para la organización de la convivencia, se produjo un ámbito cultural ajeno a los sujetos, muy alejado de las vivencias conjuntivas de las comunidades tradicionales ${ }^{30}$. Se generó así una sociedad fragmentada, polarizada; una sociedad compuesta por una diversidad de visiones del mundo, radicadas en aspiraciones heterogéneas ${ }^{31}$, y polarmente enfrentada por mor de los respectivos intereses de aquéllas.

${ }^{28}$ Nuevamente es Loader quien ha logrado presentar mejor el contraste entre la postura que Mannheim adopta y el ambiente universitario alemán de la época, en el que el historicismo impregnaba una teoría de la cultura basada en la creencia en la posibilidad de que una élite formada reorientaría hacia un porvenir prometedor los destinos de la nación. Vid. C. LOADER, op. cit., pp. 15 y ss.

${ }^{29}$ En este punto, para glosar a Mannheim he asumido - creo que sin forzar el sentido de sus apreciaciones - el enfoque general que sobre la génesis de la sociología propone Martín López. Vid. E. Martín López, «La hipertrofia de la sociología como razón de ser de la psicología social», en J. R. Torregrosa y B. Sarabia (comps.), Perspectivas y contextos de la psicología social, Barcelona, Hispano Europea, 1983, pp. 117-145.

${ }^{30}$ Mannheim habla del conocimiento conjuntivo como característico de la vida de una comunidad cohesionada en torno a una visión del mundo, que sería fruto, a su vez, de la experiencia vital compartida, y lo opone al saber comunicativo, correspondiente al ímpetu de la «civilización» (de acuerdo con el empleo de ese término por Alfred Weber) que sería ese modo abstracto de intercambio de experiencias entre esferas culturales heterogéneas y disgregadas entre sí, propio de una sociedad desarrollada y carente de unidad cultural, y que encuentra su refinamiento paradigmático en la comunicabilidad del lenguaje abstracto de las ciencias naturales. Cfr. K. MANnilem, «A sociological theory of culture and its knowability», op. cit., pp. 191 passim.

${ }^{31}$ Mannheim habla de world aspirations, refiriéndose a las tendencias que se orientan a 
Frente a ese antagonismo, la remota posibilidad de conciliación y de orientación conjunta de la vida social parecía quedar ingenuamente confiada a un vano intento. Se pretendía establecer una nueva universalidad — que Alfred Weber había denominado civilizadora-, que habría de estar basada, precisamente, en el modelo abstracto, de espíritu progresivo y ahistórico, de las ciencias naturales (es decir, inspirada por el mismo aliento que había dado origen a las deformidades que se querían ahora paliar). Mannheim entiende que el propio origen de la sociología científica está ligado a ese intento.

Para Mannheim, el pluralismo de la competición atomista y el empeño de unificación basado en ese conocimiento civilizador (que no deja de ver como una forma grosera de reificación de un método intelectual, del que se había contagiado la sociología, no apto para el ámbito de la cultura) eran elementos complementarios de un proceso esencialmente negativo, correspondiente al lado oscuro de la crisis cultural ${ }^{32}$. De alguna forma, su proyecto de sociología del espíritu (o de la cultura en su más amplio sentido), primero, y la sociología del conocimiento, después, los concibe como medios de respuesta frente a esos fenómenos deformadores; deben servir para reconocer una situación que se ha hecho extremadamente compleja, y cuyo reconocimiento es necesario para que los sujetos sociales puedan actuar orientados en un mundo lacerado por una formidable crisis de orientación.

Se podría decir, entonces, que en la tarea en pos de una sociología de la cultura, que prolonga durante la década de los veinte, Mannheim busca refinar el procedimiento de análisis, para adentrarse en el diagnóstico y poder activar la terapia adecuada frente a los problemas de desorientación colectiva y subjetiva que acarrea la disgregación espiritual que lastra a Europa llevándola camino de la catástrofe. Esta intención domina en sus Ensayos de sociología de la cultura, donde puede leerse esta exhortación:

«tenemos que encararnos, pues, con el problema de cómo desarrollar una visión integral de las relaciones humanas, dentro de nuestro estado actual de conocimiento fragmentado o, si es necesario, a partir de él. Debemos aprender a observar los hechos aislados en sus correlaciones y a ajustar los segmentos de visión en una perspectiva sintetizada. La cuestión apunta al problema de que la Sociología del espíritu debe ser considerada como la contrapartida de la Ciencia de la sociedad. Puesto que la sociedad constituye la estructura común de la interacción, la ideación y la comunicación, la sociología del espiritu es el estudio de las funciones mentales en el contexto de la acción. Por este camino es por donde debemos esperar una de las respuestas posibles a la síntesis que necesitamos» ${ }^{33}$.

cumplir las metas que articula una visión del mundo, y las caracteriza como «la unidad de estilo más profunda que es propia de la conciencia de la comunidad en todas sus objetivaciones, en las conscientes y las inconscientes». K. MANNHEIM, «A sociological theory of culture and its knowability», op. cit., p. 233.

${ }^{32}$ Cfr. ibidem, pp. 154-156. En lo que respecta a la sociología, vid., v. g., pp. 261-262.

33 Mannieim, Ensayos de sociología de la cultura, op. cit., p. 42. En ese mismo contexto, 
Tampoco puede dejarse de lado que la caracterización de la propia sociología del conocimiento como «dinámica» responde al deseo de romper con los planteamientos estáticos en el estudio de la vida social en general y de las representaciones colectivas en concreto, pues los planteamientos estáticos, del tipo que fueran, los había barrido por debajo del margen de aceptabilidad la propia fuerza de la movilidad formidable de la época. Una movilidad que se hacía especialmente llamativa en la esfera política.

Es útil aquí acudir a su ensayo «Konservatism», donde describe la génesis del conservadurismo ideológico apoyándose en cuatro factores. Tres de ellos son comunes con los que menciona para describir el origen específico de la sociología de la cultura dentro de las ciencias sociales: a) el contexto históricosocial se había hecho dinámico; b) el dinamismo tomó de manera creciente la forma de una diferenciación social, en la que unos grupos continuaron el proceso y otros lo obstaculizaron; $c$ ) las ideas y las aspiraciones con ellas conectadas se diferenciaron de acuerdo con líneas paralelas a las de la diferenciación social. El cuarto y nuevo factor en ese retrato era, precisamente, el carácter crecientemente político que tomaba la diferenciación social ${ }^{34}$. La política se convertía poco a poco en el centro en el que se aglomeraban las corrientes espirituales, de modo que vino a tomar la forma de una constelación de pretensiones, de proyectos antagónicos de conformación del mundo ${ }^{35}$.

En ese contexto histórico, la actividad política consiste en aquella parte de la experiencia constituida por las visiones del mundo en las que las fuerzas políticas están comprometidas ${ }^{36}$.

No es que Mannheim piense que el elemento político tuviera primacía sobre los demás en el contexto histórico que estaba presentando, sino que entendía que la caracterización del ambiente espiritual podía hacerse mejor, en este caso, partiendo de las corrientes políticas, entendidas como pretensiones de llevar a la práctica determinadas visiones del mundo: se hacía especialmente visible en ellas el carácter mismo de la época. La razón para que esto fuera así estribaba, según él, en la creciente fragmentación intelectual en el ámbito de las representaciones públicas de la realidad. Una fragmentación que hacía que fuesen mucho más reconocibles en ese terreno las diferentes corrientes de la vida social, y que fuesen especialmente visibles en la lucha política: se iban elevando al plano

Mannheim remacha la idea, eludiendo cualquier asomo de pretensión filosófica: «La sociología del espíritu se concibe como una visión integrada de la acción social y el proceso mental, y no como una nueva filosofía de la historia.»Ibidem, p. 42.

${ }^{3+}$ Cfr. Mannheim, «El pensamiento conservador», en K. Mannhieim, Ensayos sobre sociología y psicología social, México, Fondo de Cultura Económica, 1963 (v. o., 1927), pp. 84-183. Para lo que nos concierne, vid. pp. 89-114, especialmente pp. 113-114. Es una versión abreviada de su memoria de habilitación: Alkonservatismus: ein Beitrag zur Soziologie des Wissens (1925), que permaneció mucho tiempo inédita y ha sido publicada íntegramente en los años ochenta: Konservatismus: ein Beitrag zur Soziologie des Wissens, Frankfurt am Meine, Suhkamp, 1984.

${ }^{35} \mathrm{Cfr}$. «El pensamiento conservador», op. cit., pp. 106-111. Visto desde esta perspectiva, el conservadurismo consistía en un tradicionalismo devenido histórica y políticamente consciente.

36 Cfr. ibidem, esp. p. 93. 
consciente, haciéndose así susceptibles de tratamiento científico. Por eso dirá que la historia de las ideas políticas es «un centro de orientación válido para una visión general del contexto global» ${ }^{37}$.

En las obras anteriores al período en el que nos fijamos, la atención de Mannheim se había vuelto con insistencia sobre el contraste, que Tönnies formuló magistralmente, entre la unidad de la cultura tradicional (medieval), de carácter religioso, y el pluralismo cultural de las sociedades complejas ${ }^{38}$; pero en este período de transición el énfasis recae decididamente sobre la situación contemporánea y, ante todo, sobre el carácter político de ese pluralismo.

Al tratar el problema paradigmático del pensamiento conservador, ya había señalado que tras la Revolución Francesa se desarrolló «una tendencia polarizadora en el pensamiento»: los estilos de pensamiento se desarrollaron en sentidos extremos muy marcados. La base de esa polarización, especialmente acusada en Alemania, fueron las diferencias políticas que se produjeron bajo la presión de los acontecimientos revolucionarios franceses ${ }^{39}$. Esa insistencia de Mannheim en la polarización política del pensamiento se hace todavía más patente en el ensayo de 1929 sobre la competencia en el mundo del espíritu ${ }^{40}$.

Dicho trabajo es el texto correspondiente a su intervención en el sexto Congreso de los sociólogos alemanes, de 1928. En él manifiesta su acuerdo con L. von Wiese, quien había señalado en el curso de la reunión -siempre con palabras de Mannheim - «que la competencia debe considerarse no sólo como un rasgo de la vida económica, sino de la vida social en general», y se propone describir el papel que dicho fenómeno juega «como elemento determinante de la vida intelectual» ${ }^{41}$.

37 Cfr. ibidem, pp. 84-95, esp. 84-85 y 94-95. Una observación clara sobre la cierta autonomía y no prioridad de la esfera política puede encontrarse también en el artículo sobre las generaciones. Cfr. K. Mannheim, «Das Problem der Generationen» (1928), en Wissenssoziologie, Kurt H. Wolf (ed.), Neuwied, Luchterhand, 1970, pp. 509-565. Traducido al inglés como «The Problem of Generations», en Essays on the Sociology of Knowledge, Paul Kecskemeti (ed.), Londres, Routledge and Kegan Paul, 1952, pp. 276-322. Para la referencia, p. 557 de la versión alemana y p. 314 de la inglesa. La cita procede de la nota al pie recogida en esas páginas.

${ }^{38}$ F. Tönnies, Comunidad y asociación, Barcelona, Península, 1979 (v. o.: Gemeinschaft und Gesellschaft, Leipzig, 1887).

34 Cfr. K. MANnifEIM, «El pensamiento conservador», op. cit., pp. 89-90. La referencia textual, de la p. 89.

40 K. Mannheim, «Die Bedeutung der Konkurrentz im Gebiete des Geistigen», en Mannheim, Wissenssoziologie, Kurt H. Wolf (ed.), Neuwied, Luchterhand, 1970, pp. 566613. Citaré la traducción inglesa: «Competition as a Cultural Phenomenon», en Essays on the Sociology of Knowledge, Paul Kecskemeti (ed.), Londres, Routledge and Kegan Paul, 1952, pp. 191-229. En su ensayo sobre las generaciones habla de polaridades (Polaritäten) de las corrientes espirituales para rechazar la idea de un Zeitgeist unitario. Cfr. K. MannHeim, «Das Problem der Generationen» (1928), op. cit., p. 557 (en la versión inglesa se habla de polar tension; cfr. p. 313).

${ }^{41}$ Es interesante observar que Mannheim se apresura también, en este trabajo, a dejar claro que su interés por reconocer el papel que la competencia juega como condicionante de la vida espiritual no hay que entenderlo «como una declaración de desenfrenado "sociologismo". Lejos estoy de sugerir que con la mera base de una explicación sociológica de la génesis de los patrones o contenidos mentales se puedan sacar directamente conclusiones 
La competencia ha adoptado en la esfera pública contemporánea la forma de la «polarización». Los grupos que antes ${ }^{42}$ competían atomísticamente se han ido concentrando, se han polarizado. La competencia entre polaridades concentradas sería el tipo característico de los procesos más modernos de agrupación. Alude a la concentración de los esfuerzos de grupos segmentados en torno a determinadas posturas, cada una de ellas caracterizada por una corriente espiritual (una visión del mundo) propia y penetrada por un proyecto de configuración del mundo. Se trata, por lo tanto, de la concentración de diferentes aspiraciones singulares en un contexto de significado concreto. Al absorber diversos grupos, la propia corriente espiritual se modifica de alguna manera, de forma que la relación entre el grupo concreto y el contexto más amplio de significación es recíproca, no perdiendo aquél totalmente su identidad. La diferencia de esas nuevas especies de comunidad cultural estriba precisamente en que la competencia es necesaria para que existan ${ }^{43}$.

Como señala parafraseando a Heidegger, esa competencia es esencialmente una lucha por el dominio de la «interpretación pública de la existencia» ${ }^{44}$. Es de importancia decisiva la naturaleza que tenga la interpretación del mundo que resulta ser de general aceptación en un momento determinado. Y Mannheim entiende que «no es ése un asunto de lo que se llama "opinión pública", la cual es comúnmente reconocida como un fenómeno superficial de psicología colectiva, sino del repertorio del conjunto de nuestros significados fundamentales, con arreglo a los cuales experimentamos tanto el mundo exterior como nuestras respuestas interiores». Como el hombre «al existir en el mundo no existe en un mundo en general, sino en un mundo de significados, interpretado de forma particular», surge la disputa por el control de esa interpretación global que será objeto de aceptación general ${ }^{\text {t5 }}$.

En ese trabajo, Mannheim atiende también a las reflexiones de Heidegger

sobre su verdad y validez». Entendemos que esa ponderada postura intelectual es un rasgo habitual de su talante científico y una característica general de su sociología del saber: conviene fijar la atención en la aclaración que Mannheim hace seguidamente acerca de su comprensión de la competencia como un factor codeterminante de los fenómenos mentales. Cfr. ibidem, pp. 191-192. Para la cita del texto principal, p. 191.

${ }^{42}$ Ese «antes», según Mannheim, refiere al período histórico subsiguiente a la ruptura del «monopolio eclesiástico». Los tipos «consenso», «monopolio», «competencia atomística» y «concentración polarizada» los propone Mannheim como las modalidades históricas de establecimiento de la interpretación pública de la realidad. Cfr. ibidem, p. 198.

${ }^{43}$ Así - y proponiendo la génesis del sustrato ideológico del partido conservador alemán como ejemplo concreto de la formación de una ideología a partir de la competición y de la selección sociales-, Mannheim escribe: «Aquí, como ocurre siempre, se puede ver que una postura intelectual o volitiva, o cualquier tipo de interpretación de la realidad, no aparece súbitamente desde ninguna parte, sino que surge a partir de una variedad de creencias e impulsos propios de grupos que compiten entre sí, por medio de un proceso de selección.» Ibidem, pp. 211-212. Lo mismo dirá también de la fundamentación marxista del socialismo. Cfr. ibidem, p. 213.

t En el artículo que venimos mencionando, Mannheim cita, como ya había hecho el año anterior en su trabajo sobre el problema de las generaciones, el libro de Heidegger Sein und Zeit (1927). Cfr. MannHEIm, ibidem, p. 196.

45 Cfr. ibidem, p. 197 (también para las citas). 
sobre el sujeto colectivo impersonal (das Man) que nos dotaría de la interpretación pública de la experiencia que prevalece. Señala que esa interpretación prevaleciente es la que hace, en primer lugar, que «veamos el mundo» (que seamos capaces de captarlo, de interpretarlo unitariamente) y, en segundo término, que lo veamos de una forma preconcebida. Mannheim recuerda, en suma, la estrecha relación que hay entre ese «se» (man) y esa condición que es propia de nosotros, los hombres, que «nacemos en un mundo ya interpretado». Y dice, a continuación, que si el filósofo se puede conformar con mirar a ese «algo secreto» e impersonal, sin entrar a ver cómo surge, esto no es admisible para el sociólogo, pues su tarea empieza precisamente ahí.

Es el análisis sociológico el que va a mostrar que la interpretación pública de la realidad no está simplemente dada, ni es el fruto del pensamiento sistemático, sino la meta por la que rivalizan los hombres. Los demás elementos de conocimiento tienen su sitio en las visiones generales, y la competencia mayor va a consistir, lógicamente, en buscar el predominio de la propia visión del mundo en la esfera pública ${ }^{46}$.

Pues bien, en ese escenario es donde compiten las distintas facciones, donde cada una de las posiciones polares enfrentadas trata de establecer el monopolio interpretativo de su concepción del mundo, sin que la complementación o el diálogo entre ellas pueda producirse de forma espontánea ${ }^{47}$. Por eso, para Mannheim, la síntesis es ya una tarea agónica, correspondiente a la arena política, puesto que las posturas que entre sí compiten no surgen

«de la mera suma de elementos de pensamiento, sino, más bien, del encuentro entre aspiraciones básicas, principios formativos e interpretaciones del mundo. La fusión de esos elementos no la logra el sujeto contemplativo (siempre que sea posible separar adecuadamente al sujeto contemplativo y al activo), sino el activo y, primordialmente, el político - por cuanto la actividad orientada a cambiar el mundo es finalmente política $\gg^{48}$.

Veía, pues, la polarización cultural como una parte de un conflicto mayor entre ámbitos de experiencia, o de relaciones sociales generales. En adelante, toda su indagación sobre el condicionamiento social del pensamiento aparece

46. «Desde el punto de vista de las ciencias sociales _ escribe Mannheim- todo fragmento de conocimiento histórico relativo a la visión del mundo (weltanschaulich) y sociológico (incluso si probara ser una Verdad Absoluta en sí mismo) está claramente arraigado en, y es portado por, el impulso hacia el poder y la validez de grupos sociales particulares que quieren hacer universal su interpretación.» Cfr. ibidem. La cita es de las pp. 196-197.

47 Cfr. ibidem. Ya en Konservatism, Mannheim había señalado que el conservadurismo no podía entenderse sino en función de su antagonista político, el liberalismo. En Ideología y utopia estas explicaciones por oposición se harán más complejas, al analizarse las interrelaciones en una constelación múltiple de fuerzas históricas autoconscientes: conservadurismo burocrático, historicismo conservador, pensamiento liberal burgués, socialismo, fascismo. Vid. K. Mannheim, Ideologia y utopia, México, Fondo de Cultura Económica, 2." ed., 1987 (v. o., 1929), pp. 104 y ss.

18 Mannhlim, «Competition...», op. cit., p. 195. 
inundada por ese nuevo espíritu de síntesis, a cuyo servicio se consagra, como disciplina auxiliar de primer orden, la sociología del conocimiento.

Una comprensión cuidadosa de este asunto hace ver enseguida que su posición no consiste en una débil renuncia relativista, desfondada de voluntad de verdad, sino en una postura altamente consciente que denomina «relacionismo ${ }^{49}$, y que ya había empleado antes de la publicación de Ideologie und Utopie, como puede verse en el siguiente pasaje:

«Que ciertos objetos de conocimiento no son susceptibles de una interpretación y formulación absoluta no significa que sean arbitrarios y subjetivos, sino, únicamente, que son función de un punto de vista o de una perspectiva particular; es decir, que ciertos rasgos cualitativos de un objeto que se ba encontrado en el proceso vital de la bistoria sólo son accesibles a mentes dotadas de una estructura determinada. En los objetos que existen históricamente hay rasgos cualitativamente diferenciados que sólo están al alcance de la percepción de una conciencia diseñada y formada a través de determinadas circunstancias históricas. Esa idea de la "relatividad existencial" de ciertos objetos de conocimiento -que la escuela fenomenológica, junto a alguna otra, está poniendo de relieve con claridad creciente- está lejos de implicar un relativismo según el cual todos y nadie están en lo cierto; lo que más bien implica es un relacionismo que dice que ciertas verdades (cualitativas) no pueden ser captadas o formuladas sino en el marco de una relación existencial entre sujeto y objeto» ${ }^{50}$.

Es la suya, por lo tanto, una postura intelectual ejemplar, atenta y ardientemente comprometida, pero comprometida ante todo en la tarea de

49 Loader ha insistido en el sentido intrínsecamente político del relacionismo que Mannheim defiende en Ideología y utopía. Se trata de una doctrina que intenta principalmente la ampliación de la visión sobre la realidad política: «El relacionismo - dice Loaderofrecía un nuevo estándar de validez, que él contrastaba con el relativismo... El relativismo no niega la existencia de la verdad universal; niega simplemente que esta verdad pueda ser aprehendida por ningún sujeto concreto; en la terminología de Mannheim, el sujeto concreto estaba existencialmente ligado (limitado en su perspectiva), mientras que la verdad misma era universal. La otra alternativa, el relacionismo, abandonaba la teoría epistemológica más antigua de una verdad eterna en favor de una "verdad" que cambiaba continuamente. Al abandonar el concepto de verdad absoluta, buscaba "descubrir en la totalidad del complejo histórico el papel, la significación y el significado de cada elemento componente" para mostrar que todos los elementos tienen entre sí una interrelación, pero que esa totalidad de relaciones estaba siempre cambiando. No es ésta una visión completa y estable. La totalidad significa una intención hacia el todo que asimila las visiones particulares y, entonces, las quebranta. Representa el proceso continuo de expansión de conocimiento, y no tiene como meta el logro de una conclusión supratemporalmente válida, sino la extensión más amplia posible de nuestro horizonte de visión.» C. LOADER, $O p$. cit., p. 113. Los textos citados por Loader corresponden a una de las ediciones inglesas de Ideología y utopía, distinta a la que he manejado $(o, t a l$ vez, como en algunas ocasiones hace este autor sin advertirlo claramente, se trata de traducciones suyas al inglés desde el original alemán, pero en este caso no he podido comprobarlo; Loader cita siempre con referencias dobles a las ediciones alemana e inglesa cuando éstas existen).

50 Mannhlim, «Competition...», op. cit., p. 194. El énfasis es de Mannheim. 
orientar inteligentemente el cambio social. Trata de discernir, con espíritu riguroso y no partidista, las unidades particulares en las que se había fragmentado la cultura, con objeto de que la nueva orientación - por la que apuesta vigorosamente sabiendo que habrá de abordarse en la escena política- no se intente en abstracto, en el vacío que supondría el ignorar las razones de fondo de un pluralismo de interpretación insoslayable, que es el núcleo mismo del problema crítico que habría que afrontar.

El reconocimiento de esa posición admirable es lo que ha llevado a Ricoeur a subrayar - comentando los rasgos principales de su teoría de la ideología- la «dramática honestidad de Mannheim», que aborda sin titubeos y con acento autocrítico «una situación de colapso intelectual», en la cual, y ante el derrumbe de todo criterio común de validez, todos «somos presa de un proceso recíproco de sospechas ${ }^{51}$.

Para Mannheim, todo lo que la ciencia puede pretender es un análisis sintético de la realidad, y no ya la síntesis cultural por la que antes había trabajado. Creía que la sociología, y específicamente la sociología del conocimiento, podría contribuir privilegiadamente a una percepción global de la situación, al establecer un medio común de análisis, un lenguaje común para la comunicación intercontextual. En este sentido, el espíritu de universalismo concreto que inspiraba su sociología del conocimiento estaba llamado a ser un instrumento de primer orden al servicio de la orientación del hombre en el mundo contemporáneo, una parte importante de ese «método para orientarse en el mundo» del que Mannheim habla en Ideología y utopía:

«Una persona que cumple constante y exclusivamente con sus tareas cotidianas no asumiría una actitud de duda frente a sí misma y a su posición, y sin embargo, a pesar de su confianza en sí, sería esclava de un punto de vista particular y parcial, hasta que ocurriera la primera crisis, que le produciría un desengaño. Sólo en el momento en que por vez primera se considerara a sí misma como parte de una más amplia situación concreta, se despertaría en ella el impulso de observar sus propias actividades dentro de una trama total... Una vez que el individuo ha empuñado el método para orientarse en el mundo, inevitablemente tendrá que ampliar el estrecho horizonte de su ciudad y aprénderá a incluirse él mismo dentro de una situación nacional y aun, más tarde, mundial. Asimismo, logrará comprender la situación de su propia generación, y su situación personal en la época en que vive, y ésta, a su vez, como parte del total proceso histórico» ${ }^{52}$.

51 Cfr. P. Ricoeur, ldeologia y utopia, Barcelona, Gedisa, 1989, p. 196.

52 Mannheim, Ideología y utopia, op. cit., p. 94. Si, además de estas palabras, se leen las reflexiones de Mannheim sobre la necesidad, para la sociología, de una investigación empírica con espíritu de síntesis teórica, de una investigación interdependiente y de una «especialización horizontal» afianzada en los objetos de estudio con espíritu interdisciplinario, tal vez las palabras de ese texto que acabamos de citar se revuelvan hacia nosotros, los científicos sociales, y nos inviten a revisar la amplitud del radio de nuestro trabajo y de nuestro pensamiento. Vid. K. MAnNheim, Ensayos de sociología de la cultura, op. cit., pp. 38-48. El énfasis es añadido. 
Pero sabía que el problema histórico no consistía en una mera tarea intelectual. Aunque exigía éste, desde luego, «aprender a pensar dinámica y relacionalmente» ${ }^{53}$, sin embargo, la síntesis dinámica real, la configuración del mundo, habría de hacerse propiamente en la arena política, y todas las contribuciones científicas en ese sentido tendrían que hacerse en contacto con las aspiraciones políticas en competencia.

Ahora bien, en este trabajo no voy a entrar en la versión proyectiva y en la aspiración a la aplicabilidad de la teoría, presentes en los últimos trechos de su obra, pues todavía quiero insistir en su crítica y en su proyecto renovador de la sociología. Pues, para él, el afán por encontrar una orientación en la crisis exigía una cuidadosa revisión crítica del procedimiento de trabajo sociológico, el cual, pudiendo y debiendo ser un medio de primer orden para el hombre contemporáneo ${ }^{54}$, parecía transformarse en un instrumento sutil al servicio de las fuerzas históricas que le amenazan gravemente.

Mannheim encuentra graves problemas epistemológicos en la asimilación acrítica de una interpretación materializada del método científico de las ciencias naturales, que opta por la cuantificación abstracta como exclusivo criterio de verdad, y también en una segmentación de las tareas, inhábil para la investigación interdependiente. Cree que una sociología orientada de ese modo reductivo no es conducente, y es inepta para dar cuenta de las realidades sociales. Pero especialmente lo es porque se cierra al reconocimiento de lo específicamente conjuntivo o relacional de la vivencia social; porque pierde de vista lo "comunicativo», podríamos decir interpretando fielmente a Mannheim, aunque con un término que él solía usar, como ya se dijo, en un sentido distinto5s. Entiendo que ésta es una de las cuestiones más promisorias que encierra, como tesoro inexplorado, la obra temprana de nuestro autor.

Encuentro, en definitiva, que su reflexión sobre el «saber conjuntivo», que va mucho más allá del campo escueto de la sociognoseología, es una sugestiva propuesta sobre esa dimensión «comunicativa» de la vida social, que obtiene como rédito de su tenaz demora en la consideración del problema del vínculo intersubjetivo. Porque la relación social no consiste sólo - y esto parece haberlo visto muy claro Mannheim - en la interacción entre formaciones sociales, como propone el discurso abstracto de una sociología de herencia racionalista, que pelea en un mundo cultural fósil, cargado de fantasmagóricas formas sociales materializadas y enajenadas de las vivencias de los sujetos, sino que se trata, más profunda y esencialmente, de una vivencia recíproca - que consiste en un

${ }_{53}$ Mannheim, Ideología y utopia, op. cit., p. 77.

${ }^{54}$ Algunos años más tarde, Mannheim escribirá sobre el imprescindible papel pedagógico y socializador de la sociología: «me aventuro a afirmar que mientras en nuestros trabajos de investigación y en nuestras escuelas y nuestros programas académicos no introduzcamos la sociología como ciencia fundamental, no seremos buenos especialistas. Seamos capaces de educar a una generación de ciudadanos. De su correcta comprensión de la sociedad en que viven puede depender el que el proceso social sea en lo futuro guiado por la razón o por la sinrazón». K. MANNHEIM, «El lugar de la sociología», en Ensayos sobre saciología y psicología social, op. cit., pp. 215-229. La cita es de la última página.

55 Véase nota 30. 
saberse vinculados, un sentirse vinculados y un quererse en la vinculación recíproca (o, por el contrario, en ignorarlo, no sentirlo o no quererlo)-, que protagonizan seres de carne y hueso afrontando y poniendo en juego, cada uno y en cada caso, el destino de la especie humana.

Si lo social no puede pensarse sin una mirada clara sobre el aspecto formal, organizativo y productivo de la vida social, menos aún resulta pensado cuando la reflexión se desentraña alejándose del pulso vivo de las relaciones existenciales que constituyen en esencia la socialidad humana. He ahí una parte de la herencia intelectual de Mannheim que viene reclamando su sucesión.

\section{COROLARIO}

Lo que propongo es que el lugar que ha de reconocerse a Mannheim en la sociología se entiende a partir de los escritos teóricos de los primeros años, que podríamos denominar de asentamiento y definición intelectuales.

Además, las obras de esa primera época son importantes para estudiar su evolución intelectual. Permiten ver cómo, una vez cumplido - aunque sólo fuera sumaria y débilmente- su empeño inicial de abordar los problemas de la crisis espiritual europea en el plano filosófico, se produce la transición hacia la sociología. El cambio se concretaría poco después en sus trabajos de sociología del conocimiento, concluyendo con los intentos de establecer las bases idóneas para la organización de la democracia.

Cabe decir, salvando las distancias terminológicas e históricas y penetrando en la entraña misma de su obra, que buena parte de sus propuestas en el terreno de la sociología de la cultura y de la sociología del conocimiento nutren un enfoque teórico que se aproxima a aquellos empeños de revisión de la sociología - propuestos en las últimas décadas, pero anticipados a comienzos de siglo por algunos autores-que sitúan, junto a la dimensión productivo-organizativa de la vida social y en plano de igualdad con ella, la dimensión comunicativa (probablemente, Mannheim habría hablado de dimensión conjuntiva o integradora en este punto). Dicha dimensión ha estado ensombrecida en la tradición sociológica, y su omisión ha impedido el desarrollo armónico de la sociología. En su lugar se ha producido, tantas veces, un remedo de ciencia, una sociología de mirada absorta y obsesiva, incapaz de imaginar ni pensar la sociedad bumana sin las deformaciones características de la sociedad industrial, esa pobre sociedad nuestra, hipertrofiada en su aspecto productivo y depauperada en su dimensión comunicativa (es decir, alejada del hombre: no social, inbumana).

A partir de los escritos de los años veinte se ve cómo la tarea de Mannheim aparece presidida por el problema de la orientación del ser humano en un mundo complejo en continuo proceso de cambio, cuyo dinamismo se ha acelerado considerablemente con el progreso de la sociedad industrial; pero, en ese punto, su reflexión se curva, además, sobre los problemas de la relación entre la teoría y la praxis que atraviesan de parte a parte la propia posibilidad de 
consolidación de las ciencias humanas, y en especial de la naciente sociología, a cuya fundamentación teórica consagró toda la energía de su entendimiento.

Que es un escritor especialmente preocupado por el problema del compromiso político de los intelectuales es algo que no puede ser objeto de duda, porque, al margen del poder demostrativo que al respecto tienen los lugares más frecuentados por los comentaristas, resulta cada vez más claro que no fue otra la cuestión nuclear que prendiera en su espíritu moviéndole a escribir su obra más divulgada, Ideología y utopia $a^{56}$, que se vertebra en torno a la cuestión planteada con vigor por Max Weber en sus conferencias sobre el político y el científico. Digno de mención es que tratara el papel histórico y la propia autonomía funcional de la sociología científica con la vista puesta en ese problema, y en los términos precisos de su posible contribución para la orientación del hombre contemporáneo en una situación crítica.

Durante toda su vida intelectual, Mannheim apuesta con una finura y una grandeza dignas de admiración por la independencia en relación con las banderías políticas, mientras, paradójicamente, defiende la necesidad del compromiso del intelectual con los acuciantes problemas políticos de reorganización de la vida social. Quiero subrayar que detrás de esa paradoja no debe encontrarse una contradicción, sino aquel aliento unitario de un pensamiento de la conciliación y del arraigo que se siente obligado a sumergirse en la entraña poliédrica de un mundo roto en una pluralidad de Weltanschauungen, contradictorias entre sí y que se enfrentan en la arena de la vida social, sin que exista, al parecer, una acordabilidad básica que pueda facilitar la convivencia entre ellas. Lo mismo hay que ver en su doble dedicación, durante los últimos años de su vida, a los problemas del consenso mínimo sobre los valores fundamentales, necesario para cualquier intento de planificar la democracia dando el mayor espacio de juego a la libre creatividad de los seres humanos, y a la investigación correlativa sobre el tipo de educación que podría propiciar la nueva organización de la vida social.

Por eso, toda comprensión de la sociología del conocimiento de Mannheim, e incluso toda interpretación de su Ideología y utopía, que pierda de vista la prioridad teórica que para éste tiene la tematización de lo utópico ${ }^{57}$-entendido como el embate cuestionador contra lo inservible de la organización de la vida

56 Entiendo que la argumentación de Loader sobre este punto es consistente y digna de atención, y eso a pesar de y frente al aparato crítico con que H. E. S. Woldring intenta mantener el carácter decisivo de la influencia del marxismo de Lukàcs en la génesis de Ideologie und Utopie. Vid. C. LOADER, op. cit., pp. 95-124, y H. E. S. WOLDRING, op. cit., pp. 146 y ss.

${ }^{77}$ Cfr. H. Freyer, «Das Problem der Utopie», Deutsche Rundschau, vol. 143 (1928), pp. 321-345. Pero especialmente digno de atención es el renovador planteamiento de la polaridad ideología-utopía propuesto por P. Ricoeur, en su libro Ideología y utopia, que, considerado desde el seno de la hermenéutica del pensador francés - altamente consciente, en mi opinión, de lo que, siguiendo a R. Ramos, podemos llamar «reflexividad constitutiva de la acción social»-, constituye un auténtico filón desde el que se puede impulsar el avance de la investigación sistemática sobre las representaciones colectivas, que debe ayudar a superar el estado presente de la teoría sobre la orientación y la comunicación en la sociedad humana. Vid. P. Ricocur, Ideologia y utopia, op. cit. Cfr. R. RAmos, «Una aproximación a las paradojas de la acción social», op. cit. 
social, que se canaliza en la zona creativa de las representaciones colectivas a partir de la propia vitalidad inagotable de la existencia comunitaria - vendría a ser vacía y desorientada; por lo mismo, cabe afirmar que resultaría desviado cualquier intento de penetrar el sentido de la especificación de su pensamiento en los años veinte, sin tomar conciencia de ese crecimiento de énfasis en la atención al ámbito de lo político.

No sólo en esos aspectos que menciono, sino en su sentido global, su obra exhibe la coherencia de una tarea unitaria que se despliega en las diferentes líneas de trabajo - metodológicas, expositivo-descriptivas y sistemáticas- necesarias para establecer, en primer término, el diagnóstico de la crisis de la civilización y de los sistemas políticos, para, más tarde, procurar una propuesta para la dirección de los procesos de reorganización y reorientación de las sociedades modernas; una tarea que está presidida por el propósito explícito de fortalecer los procesos de democratización, los únicos que, para él, pueden salvaguardar la libertad; los únicos que pueden guardarla y permitir su despliegue realizativo y creador frente a las tentaciones de regimentación totalitaria ${ }^{58}$ de diverso signo, que crecían imparablemente - y cuyo peligro parece, desgraciadamente, revolver sobre nosotros el ciclo de la historia-, ante la falta de poder integrador del liberalismo de signo individualista que había sentado el patrón organizativo de la sociedad moderna.

Una sociedad que temblaba y tiembla en «estado caótico» y que, apestada «de sucesivas crisis de desintegración», no fortuitas, sino «inherentes al sistema» ${ }^{59}$, produce «una general desorientación» ${ }^{60}$, una situación de «colapso espiritual», si se me permite decirlo remedando la fortaleza expresiva del lenguaje que Karl Mannheim empleaba hace más de cincuenta años.

58 Mannhejm, Libertad, poder y planificación democrática, México, Fondo de Cultura, 1953 (v. o., 1950), pp. 50-51.

59 Cfr. ibidem, pp. 23-60. La cita, de la p. 42.

(1) Ibidem, p. 36. 


\section{BIBLIOGRAFIA}

Bauman, Z. (1978): Hermeneutics and Social Science, Londres, Heinemann.

Concidom, L. (1977): «Karl Mannheim as Philosopher», Journal of European Studies, 7 , pp. 1 -18.

FREYLR, H. (1928): «Das Problem der Utopie», Deutsche Rundschau, vol. 143, pp. 321 345.

Hekman, S. (1986): «Re-interpreting Mannheim», Theory, Culture and Society, 3, 1, pp. 137-142.

KeTt'Ler, D.; Me!A, V., y Stehr, N. (1984): Karl Mannbeim, Londres y Chichester.

LAmo de Espinosa, E. (1990): La sociedad reflexiva, Madrid, CIS.

LOADER, C. (1985): The Intellectual Development of Karl Mannheim: Culture, Politics and Planning, Cambridge University Press.

ManNheim, K. (1918): «Seele und Kultur», en Kurt H. Wolf (ed.), Wissenssoziologie, Neuwied, Luchterhand, 1970, pp. 66-84.

- (1922): «The Distinctive Character of Cultural-Sociological Knowledge», en Mannhejm, Structures of Thinking, compilado por D. Kettler, V. Meja y N. Stehr, Londres, Routledge and Kegan Paul, 1982, pp. 31-139.

- (1924): «A sociological theory of culture and its knowability», en MannHE1M, Structures of Thinking, compilado por D. Kettler, V. Meja y N. Stehr, Londres, Routledge and Kegan Paul, 1982, pp. 141-248.

- (1924): «El historicismo» (1924), en G. E. Remmling (comp.), Hacia la sociologia de conocimiento, México, FCE, 1982, pp. 141-157. Se trata de una versión que recoge la introducción de la versión original, «Historismus», en Archiv für Sozialwissenschaft und Sozialpolitik, 52, 1 (1924), pp. 1-60.

- (1928): «Das Problem der Generationen», Kölner Vierteljabresbefte für Soziologie, VII, 2: 157-185; 3: 309-330. Reproducido en Wissenssoziologie, Kurt H. Wolf (ed.), Neuwied, Luchterhand, 1970, pp. 509-565. Traducido al inglés como «The Problem of Generations», en Essays on the Sociology of Knowledge, Paul Kecskemeti (ed.), Londres, Routledge and Kegan Paul, 1952, pp. 276-322.

- (1929): «El pensamiento conservador», en Ensayos sobre sociologia y psicología social, México, Fondo de Cultura Económica, 1963 (v. o., 1927), pp. 84-183. Es una versión abreviada de su memoria de habilitación: Alkonservatismus: ein Beitrag zur Soziologie des Wissens (1925), publicada como Konservatismus: ein Beitrag zur Soziologie des Wissens, Frankfurt am Meine, Suhrkamp, 1984.

- (1929): «Die Bedeutung der Konkurrentz im Gebiete des Geistigen», en Mannheim, Wissenssoziologie, Kurt H. Wolf (ed.), Neuwied, Luchterhand, 1970, pp. 566-613. Se cita la traducción inglesa: «Competition as a Cultural Phenomenon», en K. MANNHEIM, Essays on the Sociology of Knowledge, Paul Kecskemeti (ed.), Londres, Routledge and Kegan Paul, 1952, pp. 191-229.

- (1929-1931): Ideologie und Utopie, 5." ed., Frankfurt am Meine, G. Schulte-Bulmke, 1969. Traducción inglesa: Ideology and Utopia, de Louis Wirth y Edward Shils, Nueva York, Harcourt Brace Jovanovich, s. f., y Londres, Routledge and Kegan Paul, 1936 (última: 1991). Traducción española: Mannheim, Ideología y utopia, México, Fondo de Cultura Económica, 1936; 2. ${ }^{a}$ ed., 1987.

- (1930-35): Ensayos de sociología de la cultura, Madrid, Aguilar, 1963.

- (1950): Libertad, poder y planificación democrática, México, Fondo de Cultura Económica, 1953.

Martín López, E. (1969): Sociología general I: la sociología como ciencia de las relaciones sociales, Barcelona.

- (1983): «La hipertrofia de la sociología, como razón de ser de la psicología social», en J. R. Torregrosa y B. Sarabia (comps.), Perspectivas y contextos de la psicologia social, Barcelona, Hispano Europea, pp. 117-145.

RAmos, R. (1992): «Una aproximación a las paradojas de la acción social», ponencia presentada en el IV Congreso Español de Sociología, Madrid, 24-26 de septiembre. 
Rlmmling, G. W. (1975): The Sociology of Karl Mannbeim, Londres, Routledge and Kegan Paul.

- (comp.) (1982): Hacia la sociología de conocimiento, México, FCE.

Ricoeur, P. (1971): «The Model of the Text: Meanigful Action Considered as a Text», Social Research, 38 (3), pp. 529-562.

- (1976): «Ideology and Utopia as Cultural Imagination», Philosophic Exchange, 2 (2), pp. $17-28$.

- (1977): «La structure symbolique de l'action», en Actes de la 14 Conférence de Sociologie des Religions, París, Centre National de la Recherche Scientiphique, pp. 31-50.

- (1987): Tiempo y narración, I y II, Madrid, Cristiandad (Temps et Récit, I, II y III, Seuil, 1983-1985).

- (1989): Ideología y utopia, Barcelona, Gedisa.

SÁNCHEZ DE LA YNCERA, I. (1990): Interacción y comunicación. Aproximación al pensamiento de George Herbert Mead, Pamplona, Ediciones Eunate (será reeditado próximamente).

- (1991): «Interdependencia y comunicación. Notas para leer a G. H. Mead», Revista Española de Investigaciones Soctologicas, 55, pp. 133-164.

Simonds, A. P. (1978): Karl Mannheim's Sociology of Knowledge, Oxford, Clarendon Press. Tönnies, F. (1887): Gemeinschaft und Gesellschaft, Leipzig (v. e.: Comunidad y asociación, Barcelona, Península, 1979).

Turner, B. S. (1991): «Preface to the New Edition», en Mannheim, Ideology and Utopia, nueva edición, Londres, Rouledge and Kegan Paul, pp. XXIII-LIII.

WLBER, M. (1986): El político y el cientifico, Alianza.

Wiese, L. von (1959): Sistema de sociologia general, Puebla (México), Ed. Cajica.

Woldring, H. E. S. (1985): Karl Mannheim: The Development of his Thought, New York, Saint Martin Press.

\section{RESUMEN}

Aun cuando el pormenor de este ensayo se centra principalmente en los cambios de acento que experimenta la obra de Karl Mannheim en los años veinte, cuando éste se consagró resueltamente a la sociología, el autor quiere contribuir a explicitar las razones que justifican la plena actualidad de su figura intelectual y de su obra. Sostiene que la obra de Mannheim está vertebrada con inequívoca unidad de intención y procura fijar el sentido preciso de la misma. Mannheim fue un pensador del cambio y del conflicto que consagró toda su energía intelectual a interpretar y a afrontar la crisis de orientación y participación que mina la organización de las sociedades de nuestro tiempo. Concebía la sociología como la ciencia de integración necesaria para orientar la convivencia humana en una situación cultural disgregada y altamente polarizada y compleja. Su visión de la misma apela con claridad a la condición interdependiente e intersubjetiva de la existencia y es congruente con el empeño de quienes, para superar la crisis de la ciencia de la sociedad, tratan de armonizar la sociología equilibrando los excesos estructuralistas con un adecuado tratamiento de la dimensión comunicativa de la vida social.

\section{ABSTRACT}

Althought this essay focuses mainly on the variations in emphasis suffered by Karl Mannheim's works 1920's, when he devoted himself determinaly to Sociology, it is the author's propose to help highlight the reasons justifying the absolute topicality of both his intellectual dimention and thought. It is defended that Mannheim's works are organized with a clear oneness of intention and an attemp is made to explain its meaning. Mannheim was a thinker of change and conflicit who dedicated his entire intellectual energy to interpreting and facing the crisis of orientation and participation undermining contemporary societies. Sociology was for him considered to be the science of integration, needed for 
orientation of human coexistence in a desintegrated, complex and highly polarized cultural situation. His vision of this science is firmly based on the interdependent and intersubjective quality of human existence, and it fits with the effort of those who, in orden to overcome the crisis of the science of society, persevere in harmonizing sociology by balancing struct aralist excesses with a suitable treatment of the communicative aspect of social life. 